\title{
Association between gastric content fluidity and pars oesophageal ulcers in nursery pigs: a cross-sectional study of high-risk Danish herds using commercial feed
}

Juan Miguel Peralvo-Vidal', Nicolai Rosager Weber ${ }^{2}$, Jens Peter Nielsen ${ }^{1}$, Matthew Denwood ${ }^{3}$, Svend Haugegaard ${ }^{4}$ and Anni Øyan Pedersen ${ }^{1 *}$

\begin{abstract}
Background: The objective of this cross-sectional study was to assess the within-herd prevalence of pars oesophageal ulcers (POU) in high-risk Danish herds using commercial diets. Furthermore, we aimed to estimate the association between gastric content fluidity and POU using a generalised additive model (GAM). The study included 200 clinically healthy nursery pigs randomly selected from ten farms (20 pigs from each farm). The 10 farms were selected based on a suspected high prevalence of gastric ulcers. Post-mortem gastric ulcer assessment was based on macroscopic lesions, and gastric content fluidity was assessed based on the solid particle sedimentation percentage (solid phase).

Results: We observed an overall prevalence of $35.5 \%$ for POU in nursery pigs. Within-herd prevalence varied considerably among farms, with values ranging from 0\% in Farm 1 to 84\% in Farm 4. Our model showed strong associations between POU and gastric content fluidity $(P<0.001)$, as well as between POU and farm of origin $(P<$ 0.001). In addition, we observed that the risk of POU decreased non-linearly as the gastric content solid phase percentage increased, i.e. as the gastric content became more solid.

Conclusion: We have demonstrated that pars oesophageal ulcers are present in Danish herds with nursery pigs fed commercial diets. Furthermore, we have established that gastric content fluidity is strongly associated with POU in nursery pigs. Even so, we cannot conclude that gastric content fluidity is solely responsible for POU. Future research should look into the association between pars oesophageal ulcers and both farm management activities and individual pig factors.
\end{abstract}

Keywords: Gastric ulcer, Pars oesophagea, Nursery pig, Risk factor, Gastric content, Solid phase, Ad libitum feeding

\footnotetext{
* Correspondence: anni.oeyan@sund.ku.dk

'Department of Veterinary and Animal Sciences, Section for Production, Nutrition and Health, University of Copenhagen, Grønnegårdsvej 2, 1870 Frederiksberg C, Denmark

Full list of author information is available at the end of the article
}

(c) The Author(s). 2021 Open Access This article is licensed under a Creative Commons Attribution 4.0 International License, which permits use, sharing, adaptation, distribution and reproduction in any medium or format, as long as you give appropriate credit to the original author(s) and the source, provide a link to the Creative Commons licence, and indicate if changes were made. The images or other third party material in this article are included in the article's Creative Commons licence, unless indicated otherwise in a credit line to the material. If material is not included in the article's Creative Commons licence and your intended use is not permitted by statutory regulation or exceeds the permitted use, you will need to obtain permission directly from the copyright holder. To view a copy of this licence, visit http://creativecommons.org/licenses/by/4.0/. The Creative Commons Public Domain Dedication waiver (http://creativecommons.org/publicdomain/zero/1.0/) applies to the data made available in this article, unless otherwise stated in a credit line to the data. 


\section{Background}

Porcine gastric ulceration is a prevalent disease primarily reported in finisher pigs and sows around the world $[1,2]$. The disease etiology is multifactorial, but is associated with an increased fluidity of the gastric content [3, 4]. Risk factors such as pelleted feed, ad libitum feeding, small feed particle size, and starvation are known to predispose pigs to gastric ulceration in finisher pigs [5-7].

Reports on this disease date back as early as 1950, yet identifying pigs with gastric ulcers remains challenging due to the absence of clinical signs $[6,8]$. This is particularly true in the case of nursery pigs, where the diagnosis of gastric ulceration is generally only feasible post mortem at the abattoir. As a result, prevalence and risk factor assessment for gastric ulceration is only available for finisher pigs and sows. Although, both nursery pigs and finisher pigs are fed and raised similarly, little is known about the prevalence of gastric ulcers or the effect of gastric content fluidity on gastric ulceration in nursery pigs.

Porcine gastric ulcers are principally located in the non-glandular area of the stomach, in the pars oesophagea at the cardiac region [9]. Pigs with pars oesophageal ulcers (POU) predominantly present a highly fluid gastric content with a disrupted or non-existent $\mathrm{pH}$ layering $[4,10]$. This high fluidity of the gastric content allows direct contact of the pars oesophagea with a low $\mathrm{pH}$ gastric content and high concentrations of pepsin, which is normally restricted to the fundus of the stomach $[9,11]$. Since the stratified squamous epithelium of the pars oesophagea does not produce mucus, hyperplasia then develops as a result of prolonged exposure to the low $\mathrm{pH}$ and pepsin enzymatic activity resulting from highly fluid gastric content $[7,12]$.

Gastric ulcers in pigs have been reported in all continents, with the prevalence in finisher pigs ranging from 32 to $65 \%$ [1]. In contrast, gastric ulcers in nursery pigs are barely described in the available scientific literature. This may be because ulcers cannot be diagnosed antemortem under production conditions, or because nursery pigs are not frequently observed in abattoirs. To the best of our knowledge, the occurrence of POU in nursery pigs under commercial production conditions and the association between gastric content fluidity and POU in this age group have not previously been studied.

The primary objective of this study was to estimate the within-herd prevalence of POU in nursery pigs in ten high-risk Danish farms using commercial diets fed ad libitum. The secondary objective was to estimate the association between gastric content fluidity, measured as the solid particle sedimentation percentage, and pars oesophageal ulceration in nursery pigs.

\section{Materials and methods}

\section{Study design and study population}

This cross-sectional study was carried out in ten commercial Danish farms selected by convenience in December 2017. The inclusion criteria for farms included historic records of gastric ulceration in finisher pigs or sows, the use of commercially produced feed, and adlibitum feeding. From each of the ten farms, 20 clinically healthy nursery pigs were selected by systematic random sampling from 15 to 20 different pens. There was no sample size consideration for this study; a sample size of 20 nursery pigs was chosen because it was the number of pigs that the researcher and one animal technician were able to handle at each farm visit. Random selection was intentionally carried out in sections with the oldest nursery pigs. The 200 selected nursery pigs were all DanBred (Landrace $\times$ Yorkshire $\times$ Duroc). To reduce sampling bias, the same researcher carried out the selection process.

\section{Data collection and gastric ulcer assessment}

Pigs were euthanised by bleeding through sectioning of the jugular vein and carotid artery after stunning by captive-bolt pistol in accordance with Danish regulations for euthanasia of animals [13]. On each farm, nursery pigs were sampled within the same day from 8:00 AM to 12:00 AM. There was no feed withdrawal for all sampled pigs. All nursery pigs remained in the nursery pen with ad libitum feed access until sampling. Body weight and sex were recorded post mortem. To avoid the gastric content from spilling, stomachs were removed from the abdominal cavity, preserving $5 \mathrm{~cm}$ of duodenum and oesophagus. Upon arrival at the Laboratory for Pig Diseases, an experienced pathologist assessed the stomach health according to macroscopic lesions, based on Nielsen and Ingvartsen's scoring system [14]. According to these lesion scores, stomachs with no lesions, parakeratosis, or erosions were classified as "No pars oesophageal ulcers" (NPOU) and stomachs with ulcers, oesophageal stenosis, and scars were classified as "Pars oesophageal ulcers" (POU). Gastric content fluidity was assessed based on the solid particle sedimentation percentage (solid phase). This involved measuring the gastric content fluidity using graduated plastic beakers after $24 \mathrm{~h}$ at $4{ }^{\circ} \mathrm{C}$. Only stomachs with gastric content were included in this assessment.

\section{Feeding and feed particle analysis}

Samples of approximately $4 \mathrm{~kg}$ of feed were collected at each farm from a minimum of six different feeders or from the silos during feed loading. Then $100 \mathrm{~g}$ ( $\pm 25 \mathrm{~g}$ ) was obtained from each sample using a sample riffle splitter (c 2019, Pfeuffer GmbH). Feed particle size was assessed according to 
Mikkelsen and collaborators (2004) for wet sieve analysis of pelleted feed [15]. Sieves $\left(\right.$ Retsch $\left.^{\circ}\right)$ measuring $3150 \mu \mathrm{m}, 2000 \mu \mathrm{m}, 1400 \mu \mathrm{m}, 1000 \mu \mathrm{m}, 500 \mu \mathrm{m}$, and $355 \mu \mathrm{m}$, and a wet sieve shaker set to an amplitude of $1.5 \mathrm{~mm}$ (Retsch AS 200) were used for this purpose. Feed particle size was expressed as average particle size in $\mathrm{mm}$ (AVP), geometric mean diameter in $\mu \mathrm{m}$ (GMD), and geometric standard deviation (GSD). GMD and GSD were calculated based on the equation by Wilcox and collaborators (1970) [16]. In all visited farms commercial feed was formulated according to the Danish nutrition standards for nursery pigs and was based on wheat, barley and soybean meal [17].

\section{Statistical analysis}

The relationship between gastric ulceration (dichotomous outcome) and gastric content fluidity (solid phase percentage) was estimated using a generalised additive model (GAM) with binary response and logistic link function. Gastric content fluidity was fit using a smoothing term (thin plate regression spline), sex was fit as a fixed effect (females relative to males), and herd was fit as a random effect as descrived in Additional files 1 and 2. Entire males and castrated pigs were included as one single group. Statistical analysis was performed using $\mathrm{R}$ version 3.6.0 [18]. The mgcv package version $1.8-31$ [19] was used to fit the GAM, and the tidyverse package [20] was used to extract output and produce plots. Odds Ratios were calculated based on the GAM fit using the function or gam from the package oddsratio version 2.0.1 [21]. Posterior 95\% confidence intervals for prevalence estimates were calculated using a Bayesian method based on a conjugate Beta $(1,1)$ prior, with Highest Posterior Density Intervals calculated using the TeachingDemos package version 2.12 [22].

\section{Results}

Descriptions of the farms and feed particle size assessments are shown in Table 1. Farm size is presented as the annualized inventory of sows per year and the number of $30 \mathrm{~kg}$ pigs produced per year. The study included both small (180 sow years) and large herds (1100 sow years). Feed particle size expressed as both GMD and in mm did not vary considerably across farms. Summary statistics for gastric ulceration assessment in 200 nursery pigs are presented in Table 2, alongside the macroscopic lesion score per farm. Summary statistics for the independent variables sex (females, entire males, and castrates), body weight at sampling $(\mathrm{kg})$, and sedimentation of solid particles (\%) are presented in Table 3.

\section{Prevalence of pars oesophageal ulcers}

The overall and within-herd prevalence is presented in Table 2. Pars oesophageal ulcers were found in a total of $35.5 \%$ (range: 5 to $84 \%$ ) of nursery pigs (71 nursery pigs in total). There was a considerable variation in the prevalence of POU at herd level (Table 2), for example Farm 1 had no pigs with POU, while Farm 8 had one (5\%) and Farm 4 had 17 (85\%). In this study, POU were identified in all farms where nursery pigs were given commercial pelleted feed (Farm 2 to 10; Tables 1 and 2), while nursery pigs at Farm 1 were given an expanded meal feed and did not present POU.

Table 1 Summary of farm characteristics, production capacity, and assessment of feed particle size

\begin{tabular}{|c|c|c|c|c|c|c|c|c|c|c|c|}
\hline \multirow[t]{2}{*}{ Farm } & \multicolumn{5}{|c|}{ Herd characteristics } & \multirow[t]{2}{*}{ Feed type } & \multicolumn{5}{|c|}{ Particle size assessment } \\
\hline & $\begin{array}{l}\text { No. of } \\
\text { sows per year }\end{array}$ & $\begin{array}{l}\text { No. of } 30 \mathrm{~kg} \text { pigs } \\
\text { produced per year }\end{array}$ & $\begin{array}{l}\overline{\bar{x}} \text { No. of } \\
\text { nursery pigs / } \\
\text { pen }\end{array}$ & $\begin{array}{l}\overline{\mathrm{x}} \mathrm{m} 2 \text { / } \\
\text { nursery pig }\end{array}$ & $\begin{array}{l}\overline{\bar{x}} \text { Temperature } \\
\text { nursery room in }{ }^{\circ} \mathrm{C}\end{array}$ & & $\begin{array}{l}\mathrm{GMD} \\
(\mu \mathrm{m})\end{array}$ & $\begin{array}{l}\text { GSD } \\
(\mu \mathrm{m})\end{array}$ & $\begin{array}{l}<1 \\
\mathrm{~mm} \\
(\%)\end{array}$ & $\begin{array}{l}1-2 \\
\mathrm{~mm} \\
(\%)\end{array}$ & $\begin{array}{l}>2 \\
\mathrm{~mm} \\
(\%)\end{array}$ \\
\hline 1 & 180 & 6000 & 33 & 0.35 & 19 & $\begin{array}{l}\text { Expanded } \\
\text { meal feed }\end{array}$ & 627.8 & 2.27 & 66.7 & 19.7 & 12.6 \\
\hline 2 & 535 & 16,000 & 29 & 0.37 & 18 & Pelleted & 540.7 & 1.92 & 76.4 & 20.8 & 2.7 \\
\hline 3 & 850 & 28,000 & 22 & 0.49 & 19 & Pelleted & 635.7 & 2.25 & 67.6 & 19.6 & 12.8 \\
\hline 4 & 240 & 7400 & 35 & 0.33 & 22 & $\begin{array}{l}\text { Crushed pellets } \\
\text { (Liquid form) }\end{array}$ & 486 & 1.83 & 82.2 & 15.3 & 2.5 \\
\hline 5 & 1100 & 35,000 & 32 & 0.31 & 18 & Pelleted & 620.8 & 2.32 & 69.1 & 16 & 14.9 \\
\hline 6 & 400 & 14,000 & 19 & 0.35 & 18 & Pelleted & 532.9 & 2.09 & 76.7 & 15.2 & 8 \\
\hline 7 & 370 & 12,000 & 24 & 0.35 & 20 & Pelleted & 584.7 & 2.12 & 71.2 & 18.8 & 10 \\
\hline 8 & 400 & 11,000 & 19 & 0.46 & 17 & Pelleted & 565.8 & 2.08 & 72.8 & 19.9 & 7.3 \\
\hline 9 & 630 & 20,000 & 32 & 0.37 & 18 & Pelleted & 483.3 & 1.75 & 83.3 & 16 & 0.7 \\
\hline 10 & 700 & 23,000 & 29 & 0.38 & 18 & $\begin{array}{l}\text { Crushed pellets } \\
\text { (Liquid form) }\end{array}$ & 464.6 & 1.73 & 84.6 & 15 & 0.4 \\
\hline
\end{tabular}


Table 2 Within-herd prevalence and summary statistics for gastric lesion assessment in 200 nursery pigs $s^{\mathrm{a}}$ from 10 farms

\begin{tabular}{|c|c|c|c|c|c|c|c|c|c|}
\hline \multirow[t]{2}{*}{ Farm } & \multirow{2}{*}{$\begin{array}{l}\text { No. of } \\
\text { observations }\end{array}$} & \multicolumn{3}{|c|}{ No Pars Oesophageal Ulcers (NPOU) } & \multicolumn{3}{|c|}{ Pars Oesophageal Ulcers (POU) } & \multirow{2}{*}{$\begin{array}{l}\text { Within-Herd } \\
\text { Prevalence (No.) }\end{array}$} & \multirow[t]{2}{*}{$95 \% \mathrm{Cl}$} \\
\hline & & Healthy & Parakeratosis & Erosion & Ulcer & Scar & Oesophageal stenosis & & \\
\hline 1 & 20 & 18 & 2 & 0 & 0 & 0 & 0 & $0 \%$ & $0.87 ; 1.00$ \\
\hline 2 & 20 & 4 & 9 & 2 & 1 & 4 & 0 & $25 \%(5)$ & $0.54 ; 0.89$ \\
\hline 3 & 20 & 6 & 8 & 1 & 3 & 2 & 0 & $25 \%(5)$ & $0.54 ; 0.89$ \\
\hline 4 & 20 & 0 & 3 & 0 & 7 & 8 & 2 & $85 \%(17)$ & $0.04 ; 0.34$ \\
\hline 5 & 20 & 3 & 4 & 1 & 7 & 2 & 3 & $60 \%(12)$ & $0.21 ; 0.60$ \\
\hline 6 & 20 & 5 & 9 & 1 & 2 & 2 & 1 & $25 \%(5)$ & $0.54 ; 0.89$ \\
\hline 7 & 20 & 4 & 5 & 0 & 6 & 4 & 1 & $55 \%(11)$ & $0.25 ; 0.65$ \\
\hline 8 & 20 & 11 & 8 & 0 & 1 & 0 & 0 & $\begin{array}{l}5 \% \\
(1)\end{array}$ & $0.79 ; 0.99$ \\
\hline 9 & 20 & 5 & 8 & 0 & 3 & 4 & 0 & $35 \%(7)$ & $0.46 ; 0.82$ \\
\hline 10 & 20 & 0 & 11 & 1 & 4 & 4 & 0 & 40\% (8) & $0.39 ; 0.78$ \\
\hline Total & 200 & 56 & 67 & 6 & 34 & 30 & 7 & $35.5 \%^{\mathrm{b}}(71)$ & - \\
\hline
\end{tabular}

${ }^{\mathrm{a}}$ Danish system for gastric health assessment [14] ${ }^{\mathrm{b}}$ Overall prevalence in the study

\section{Association between gastric content fluidity and gastric ulceration}

In this study, 13 stomachs were empty at sampling and were excluded from the statistical analysis. Our generalised additive model showed that there was a strong association between gastric content fluidity $(P<0.001)$ and POU (Tables 3 and 4). This model also demonstrated a decrease in the odds of having POU as the gastric content solid phase percentage increased following a nonlinear pattern (Fig. 1). Indeed, the protective effect of solid gastric content (with low fluidity) is only apparent when the gastric content solid phase percentage increases above the range 36.8 to $52.6 \%$ (OR $0.69,95 \%$ CI: 0.48; 0.99; Table 5 and Fig. 1). However, our model identified a strong association between gastric ulceration in nursery pigs and both gastric content fluidity and the farm of origin $(P<0.001$; Table 4$)$. In addition, we did not observe an association between sex and POU in our model (Table 4 and Fig. 1).

\section{Assessment of feed particle size}

Table 1 shows the feed particle size analysis expressed both as GMD and the percentage distribution of particle size in $\mathrm{mm}$. Particle size varied to a lesser degree among the farms: Farm 4, Farm 9, and Farm 10 had the smallest particle sizes $(<486 \mu \mathrm{m}$ GMD), while Farm 3 had the largest particle size in this study at $635.7 \mu \mathrm{m}$ GMD. Interestingly, Farm 1, with a $0 \%$ prevalence of POU and using expanded meal feed, had a feed particle size of $627.8 \mu \mathrm{m}$ GMD, which is no larger than that found for Farm 3 with 25\% POU prevalence and pelleted feed.

\section{Discussion}

In this study, we observed an overall prevalence of $35.5 \%$ for pars oesophageal ulcers in clinically healthy nursery pigs. In addition, we identified a significant association $(P<0.001)$ between pars oesophageal ulceration and both gastric content fluidity (solid phase percentage) and farm of origin $(P<0.001)$. To the best of our knowledge, this is the first time that the prevalence of gastric ulceration and the role of gastric content fluidity have been assessed in nursery pigs under commercial conditions.

The prevalence presented here is comparable to results observed in finisher pigs at abattoir level in Australia (30\%), Colombia (34.8\%), USA (32\%), and Denmark (30\%) $[1,7,23,24]$. However, we cannot assume that this prevalence applies to nursery pigs in general because we only focused on high-risk herds with commercial diets fed ad libitum and with previous cases of gastric ulceration in finisher pigs or sows. Therefore, the

Table 3 Descriptive statistics for independent observations in 200 nursery pigs from 10 farms

\begin{tabular}{|c|c|c|c|c|}
\hline Independent variable & Unit & Count & Percent & SD \\
\hline \multirow[t]{3}{*}{ Sex } & Females & 87 & $44 \%$ & - \\
\hline & Entire males & 12 & $6 \%$ & - \\
\hline & Castrates & 101 & $51 \%$ & - \\
\hline Pig weight at sampling & $\mathrm{Kg}$ & 22.41 & - & 4.71 \\
\hline Solid phase $\%$ - POU nursery pigs & Average & 61.70 & - & 13.93 \\
\hline Solid phase $\%$ - NPOU nursery pigs & Average & 85.29 & - & 16.71 \\
\hline
\end{tabular}


Table 4 Generalised additive model with binary response and logistic link function for evaluating the risk of POU in 200 nursery pigs, with farm as a random effect

\begin{tabular}{lllll}
\hline Parameter & Type & Coefficients & EDF & $P$-value \\
\hline Intercept & Fixed & -1.63 & - & $<0.001$ \\
Sex (Males) & Fixed & 0.5 & - & NS \\
Farm & Random & - & $5.44<0.001$ \\
aSolid phase & Thin plate regression spline & - & $2.74<0.001$ \\
\hline
\end{tabular}

${ }^{a}$ Solid particle sedimentation percentage from the gastric content after $24 \mathrm{~h}$ at $4{ }^{\circ} \mathrm{C}$. NS Non-Significant. EDF Effective Degrees of Freedom

prevalence presented here only reflects the within-herd prevalence on these study farms.

We showed that increased gastric content fluidity (solid phase percentage) is associated with an increased risk of pars oesophageal ulcers in nursery pigs. This result is in accordance with previous observations by various researchers, who found that the physical characteristics of the feed (i.e. finely ground) and an increase fluidity of gastric content were associated with gastric ulceration $[4,10,25]$. Our model also showed an association between gastric ulcers and the farm of origin. However, this observation might be the result of only including 20 nursery pigs per farm.

The within-herd prevalence ranged from $0 \%$ for Farm 1 to severely affected herds with a prevalence of 85 and $60 \%$ for Farm 4 and Farm 5, respectively. Risk factor studies on finisher pigs have shown that feed type (i.e. pelleted feed) can have a negative effect on pars oesophageal health $[7,26]$. The variation in within-herd prevalence that we observed might be associated with the feed type, since Farm 1 used expanded meal feed, while Farm 4 and Farm 5 used pelleted feed. This is in accordance with the protective effect of meal feed on pars oesophageal ulceration previously reported in finisher pigs [27]. Interestingly, the feed used in Farm 1 was also expanded, which is associated with an increased risk of gastric lesions in finisher pigs [28]. Therefore, we cannot conclude that the sole reason for Farm 1 having no observed pars oesophageal ulcers was due to feed type. Although the genetic pool in Danish farms is highly homogeneous (DanBred), genetic factors might also be associated with the variation in gastric ulceration among farms [29, 30]. Furthermore, it is also possible that within-herd variation for gastric ulceration is the result of subclinical disease status in some nursery pigs that might have prompted some level of anorexia days before sampling. It has previously been reported that a reduced feed consumption and feed withdrawal are associated with a higher risk for gastric ulceration in finisher pigs [31, 32]. Therefore, these observations suggest that additional factors at farm or individual pig level might also play an important role in POU development.

\section{Conclusion}

The risk of pars oesophageal ulceration was significantly higher in nursery pigs with a highly fluid gastric content than in nursery pigs with a solid gastric content (reduced fluidity). However, we are not able to conclude that gastric content fluidity alone is responsible for pars oesophageal ulceration. Pars oesophageal gastric ulceration in nursery pigs appears to be a recurrent problem in herds using commercial pelleted feed. The 35.5\% overall prevalence exclusively reflects the level of gastric ulceration in the selected study herds, yet the extent of this problem varied considerably among herds. We observed nursery pigs with healthy stomachs or with only minor lesions in herds with a high prevalence of gastric

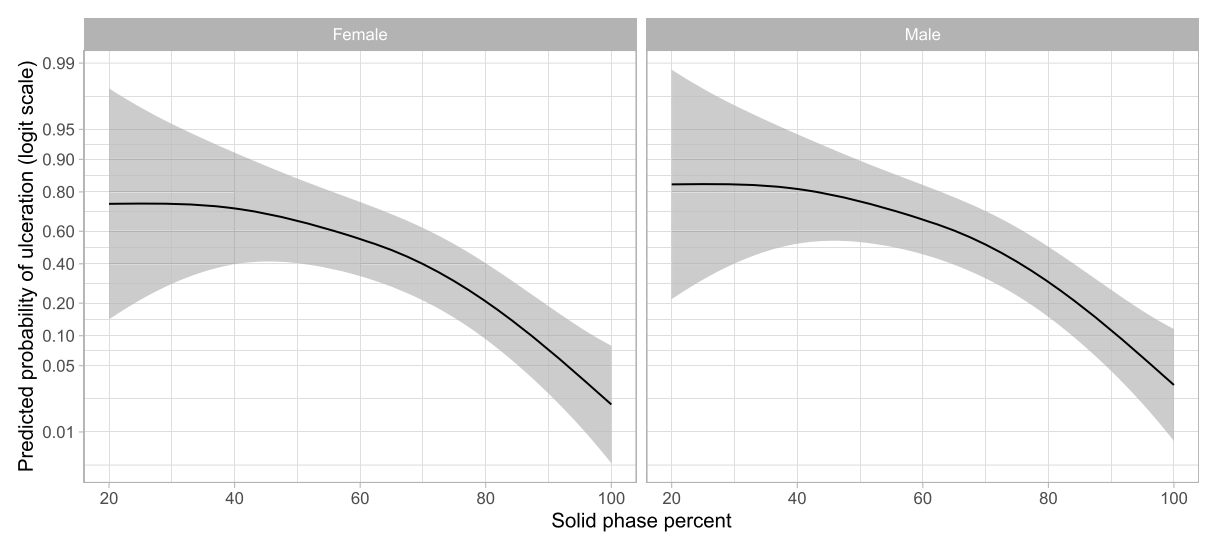

Fig. 1 Estimated relationship between gastric content fluidity and the probability of gastric ulceration in nursery pigs (Female and Male), estimated using a generalised additive model (using a smoothing term). The grey shaded area represents $95 \%$ confidence intervals for the relationship 
Table 5 Odds Ratio for POU according to the solid phase percentage as predicted based on the generalised additive model (20\% quantiles)

\begin{tabular}{lllll}
\hline Parameter & \multicolumn{2}{l}{ Solid phase range (\%) } & Odds Ratio & $\mathbf{9 5 \%} \mathbf{C l}$ \\
\hline Solid phase & $21 \%$ & $36.8 \%$ & 1.56 & $0.49 ; 4.97$ \\
& $36.8 \%$ & $52.6 \%$ & 0.69 & $0.48 ; 0.99$ \\
& $52.6 \%$ & $68.4 \%$ & 0.46 & $0.43 ; 0.49$ \\
& $68.4 \%$ & $84.2 \%$ & 0.21 & $0.20 ; 0.21$ \\
& $84.2 \%$ & $100 \%$ & 0.09 & $0.12 ; 0.07$ \\
\hline
\end{tabular}

ulcers; despite them all sharing the same environment, feed, and management practices. This implies that individual pig and farm management activities might also play an important role in the development of gastric ulceration.

\section{Supplementary Information}

The online version contains supplementary material available at https://doi. org/10.1186/s40813-021-00199-x.

Additional file 1. Statistical GAM model ( $r$ file).

Additional file 2. Raw data for the statistical GAM model.

\section{Abbreviations}

POU: Pars Oesophageal Ulcers; GAM: Generalised additive model; AVP: Average particle size in mm; GMD: Geometric mean diameter in $\mu \mathrm{m}$; GSD: Geometric standard deviation in $\mu \mathrm{m}$

\section{Acknowledgements}

The authors thankfully acknowledge the collaboration of the Danish pig producers in this study. We would also like to thank the veterinary students Mette Iversen, Kasper Pedersen, and Martin Sejersen. Similarly, the authors will like to thank Sarah Layhe for her contribution in the English proofreading of this paper.

\section{Authors' contributions}

Project conception and study design: JMPV, AØP, NRW, JPN. Sampling: JMPV, NRW. Laboratory analysis: SH, JMPV. Data analysis and Interpretation: JMPV, MD, NRW. Drafting the manuscript: JMPV, AØP, NRW, JPN, MD. All authors read, reviewed, and approved the final manuscript.

\section{Funding}

The Danish Pig Levy Foundation funded this study.

\section{Availability of data and materials}

Gastric ulceration assessment data sets and R scripts for this study are available in the following files:

\section{Ethics approval and consent to participate}

The present study was performed according to the recommendations for animal experimentation from the University of Copenhagen in compliance with Danish Animal Experiment Inspectorate regulations.

\section{Consent for publication}

Not applicable.

\section{Competing interests}

The authors have several ongoing research projects in collaboration with the agricultural sector and livestock governing bodies. The authors declare that they have no competing interests.

\section{Author details}

'Department of Veterinary and Animal Sciences, Section for Production, Nutrition and Health, University of Copenhagen, Grønnegårdsvej 2, 1870 Frederiksberg C, Denmark. ${ }^{2}$ SEGES Danish Pig Research Centre, Danish Agriculture and Food Council, Axeltorv 3, 1609 Copenhagen V, Denmark. ${ }^{3}$ Department of Veterinary and Animal Sciences, Section for Animal Welfare and Disease Control, University of Copenhagen, Grønnegårdsvej 8, 1870 Frederiksberg C, Denmark. ${ }^{4}$ Laboratory for Pig Diseases, SEGES Danish Pig Research Centre, Danish Agriculture and Food Council, Vinkelvej 13, 8620 Kjellerup, Denmark.

Received: 30 October 2020 Accepted: 2 February 2021

Published online: 23 February 2021

\section{References}

1. Doster AR. Porcine gastric ulcer. Vet Clin North Am Food Anim Pract. 2000; 16:163-74.

2. Thomson JR, Friendship RM. Digestive system. In: Zimmerman JJ, Karriker $L A$, Ramirez A, Schwartz KJ, Stevenson GW, Zhang J, editors. Dis swine. 11th ed: Wiley; 2019. p. 234-63. Available from: https://onlinelibrary.wiley.com/ doi/book/10.1002/9781119350927.

3. Argenzio RA, Eisemann J. Mechanisms of acid injury in porcine gastroesophageal mucosa. Am J Vet Res. 1996;57:564-73 Available from: http://www.ncbi.nlm.nih.gov/pubmed/8712526.

4. Maxwell CV, Reimann EM, Hoekstra WG, Kowalczyk T, Benevenga NJ, Grummer RH. Effect of dietary particle size on lesion development and on the contents of various regions of the swine stomach. J Anim Sci. 1970;30: 911-22 Available from: https://academic.oup.com/jas/article/30/6/911-922/4 697934

5. Melnichouk SI. Mortality associated with gastric ulceration in swine. Can Vet $\mathrm{J}=$ La Rev Vet Can. 2002;43:223-5 Available from: http://www.ncbi.nlm.nih. gov/pubmed/11901598.

6. Friendship RM. Gastric ulceration in swine. J Swine Heal Prod. 2004;12:34-5 Available from: www.aasv.org/shap/issues/v12n1/v12n1p34.html.

7. Robertson I, Accioly J, Moore K, Driesen S, Pethick D, Hampson D. Risk factors for gastric ulcers in australian pigs at slaughter. Prev Vet Med. 2002; 53:293-303.

8. Bullard JF. Gastric ulcer in large boar. J Am Vet Med Assoc. 1951;119:129 Available from: http://www.ncbi.nlm.nih.gov/pubmed/14850384.

9. Argenzio RA. Comparative pathophysiology of nonglandular ulcer disease: a review of experimental studies. Equine Vet J Suppl. 1999;29:19-23.

10. Maxwell CV, Reimann EM, Hoekstra WG, Kowalczyk T, Benevenga NJ, Grummer RH. Use of Tritiated water to assess, in vivo, the effect of dietary particle size on the mixing of stomach contents of swine. J Anim Sci. 1972; 34:212-6 Available from: https://academic.oup.com/jas/article/34/2/212-21 6/4666909.

11. Regina DC, Eisemann JH, Lang JA, Argenzio RA. Changes in gastric contents in pigs fed a finely ground and pelleted or coarsely ground meal diet. J Anim Sci. 1999;77:2721 Available from: https://academic.oup.com/jas/article/ 77/10/2721-2729/4653409.

12. Lang J, Blikslager A, Regina D, Eisemann J, Argenzio R. Synergistic effect of hydrochloric acid and bile acids on the pars esophageal mucosa of the porcine stomach. Am J Vet Res. 1998;59:1170-6 Available from: http://www. ncbi.nlm.nih.gov/pubmed/9736398.

13. Miljø og Fødevareministeriet. Order on the slaughter and killing of animals Bekendtgørelse om slagtning og aflivning af dyr; 2014. Available from: https:/www.retsinformation.dk/Forms/R0710.aspx?id=161815\#Not1

14. Nielsen EK, Ingvartsen KL. Effects of cereal disintegration method, feeding method and straw as bedding on stomach characteristics including ulcers and performance in growing pigs. Acta Agric Scand - Sect A Anim Sci. 2000;50:30-8.

15. Mikkelsen LL, Naughton PJ, Hedemann MS, Jensen BB. Effects of physical properties of feed on microbial ecology and survival of salmonella enterica serovar Typhimurium in the pig gastrointestinal tract. Appl Environ Microbiol. 2004;70:3485-92 Available from: http://www.ncbi.nlm.nih.gov/ pubmed/15184147.

16. Wilcox RA, Deyoe CW, Pfost HB. A method for determining and expressing the size of feed particles by sieving. Poult Sci. 1970;49:9-13 Available from: https:/academic.oup.com/ps/article-lookup/doi/10.3382/ps.0490009.

17. Tybirk P, Sloth NM, Kieldsen N, Shooter L. Nutrient requirement standards; 2017. https://pigresearchcentre.dk/Nutrient-standards 
18. R Core Team. R: a language and environment for statistical computing. Vienna: R Foundation for statistical Computing; 2020. Available from: https:// www.r-project.org/

19. Wood SN. Thin plate regression splines. J R Stat Soc Series B Stat Methodology. 2003:95-114 Available from: https://rss.onlinelibrary.wiley. com/doi/full/10.1111/1467-9868.00374.

20. Wickham H, Averick M, Bryan J, Chang W, McGowan L, François R, et al. Welcome to the Tidyverse. J Open Source Softw Open J. 2019;4:1686 Available from: https://joss.theoj.org/papers/10.21105/joss.01686.

21. Schratz P. Odds ratio calculation for GAM(M)s \&amp; GLM(M)s [R package oddsratio version 2.0.1]. Comprehensive R Archive Network (CRAN). 2020; Available from: https://cran.r-project.org/package=oddsratio.

22. Snow G. CRAN - package TeachingDemos; 2020. Available from: https:/cra n.r-project.org/web/packages/TeachingDemos/index.html

23. Bernardo R, Taborda D, Valencia F, Franco O, Ortiz L. Frequency of post mortem gastric ulcer in pigs slaughtered at Medellin (Colombia). Colvesa: Rev. Colomb. Ciencias Pecu; 2008. Available from: http://www.scielo.org.co/ scielo.php?script=sci_arttext\&pid=S0120-06902008000200004

24. Nielsen EO, Haugegaard S, Jørgensen L, Sørensen G. Gastric health in sows and slaughter pigs (in Danish). Danish Pig Res. 2013; Available from: https:// svineproduktion.dk/aktuelt/temaer/ /link.aspx?_id=8D4A6D8ABC8F4F3 E9634A5BD03FAE80B\& $z=z$.

25. Mahan DC, Pickett RA, Perry TW, Curtin TM, Featherston WR, Beeson WM. Influence of various nutritional factors and physical form of feed on Esophagogastric ulcers in swine. J Anim Sci. 1966;25:1019-23 Available from: https:/academic.oup.com/jas/article/25/4/1019-1023/4703124.

26. Gottardo F, Scollo A, Contiero B, Bottacini M, Mazzoni C, Edwards SA. Prevalence and risk factors for gastric ulceration in pigs slaughtered at 170 kg. Animal. 2017:1-9. https://doi.org/10.1017/S1751731117000799.

27. Mößeler A, Wintermann M, Sander SJ, Kamphues J. Effect of diet grinding and pelleting fed either dry or liquid feed on dry matter and $\mathrm{pH}$ in the stomach of pigs and the development of gastric ulcers. J Anim Sci. 2012;90: 343-5 Available from: https://academic.oup.com/jas/article/90/ suppl_4/343/4704202.

28. Millet $\mathrm{S}$, Kumar S, De Boever J, Ducatelle R, De Brabander D. Effect of feed processing on growth performance and gastric mucosa integrity in pigs from weaning until slaughter. Anim Feed Sci Technol. 2012;175:175-81. https://doi.org/10.1016/j.anifeedsci.2012.05.010.

29. Berruecos JM, Robison OW. Inheritance of gastric ulcers in swine. J Anim Sci. 1972;35:20-4 Available from: https://academic.oup.com/jas/article/35/1/2 $0-24 / 4699972$

30. Nafstad I. Gastric ulcers in swine. Pathol Vet. 1967;4:1-14 Available from: http://journals.sagepub.com/doi/10.1177/030098586700400101.

31. Swaby H, Gregory NG. A note on the frequency of gastric ulcers detected during post-mortem examination at a pig abattoir. Meat Sci. 2012;90:269-71 Available from: https://www.sciencedirect.com/science/article/pii/S0309174 $011002300 ?$ via\%3Dihub.

32. Lawrence BV, Anderson DB, Adeola O, Cline TR. Changes in pars esophageal tissue appearance of the porcine stomach in response to transportation, feed deprivation, and diet composition. J Anim Sci. 1998;76:788-95.

\section{Publisher's Note}

Springer Nature remains neutral with regard to jurisdictional claims in published maps and institutional affiliations.

Ready to submit your research? Choose BMC and benefit from:
- fast, convenient online submission
- thorough peer review by experienced researchers in your field
- rapid publication on acceptance
- support for research data, including large and complex data types
- gold Open Access which fosters wider collaboration and increased citations
- maximum visibility for your research: over 100M website views per year
At BMC, research is always in progress.
Learn more biomedcentral.com/submissions

